Geopolítica(s) Revista de estudios sobre espacio y poder ISSN: 2172-3958

http://dx.doi.org/10.5209/GEOP.63834

\title{
El mapa municipal en España: estructura, evolución y problemáticas
}

\author{
Abel Albet i Mas ${ }^{1}$
}

Recibido: 28 de octubre de 2018 / Aceptado: 1 de diciembre de 2018

Resumen. El mapa municipal español presenta graves disfunciones (pervivencia de pequeños municipios en población y en superficie; enclaves y límites problemáticos; atribuciones sobredimensionadas) producto de una tradición que se resiste a cambiar. Tras hacer un análisis de la evolución y de la estructura actual de la legislación sobre la planta municipal y sobre la política de alteraciones, el texto denuncia las grandes dificultades y reticencias para llevar a cabo una revisión del mapa municipal. A la administración local se le impone el reto de diferenciar el territorio "político" (ámbito de identidad y participación ciudadana, pero convertido en feudo de influencia para los partidos políticos), del territorio de "gestión", más idóneo para hacer operativa la administración pública local, asegurando el bienestar y calidad de vida para la población. El primer paso de la reforma debería ser una revisión de las atribuciones, competencias y financiación de los municipios, determinando las que pueden ser atribuidas a otras administraciones.

Palabras clave: municipio; mapa municipal; disfuncionalidades; límites municipales; administración local; España.

\section{[en] The Municipal Map in Spain: Structure, Evolution and Issues}

\begin{abstract}
The Spanish municipal map shows serious dysfunctions (persistence of small municipalities in population and on surface, enclaves and problematic boundaries, over-sized attributions) consequence of a tradition that refuses to change. After an analysis of the evolution and the current structure of the legislation on the municipal map and its changes, the text denounces the great difficulties and reluctance to carry out a systematic review of the municipal map. Local administration is challenged to differentiate the "political" territory —as the place for citizen's identity and participation but, I fact, becoming a fief of influence for political parties - , from the "management" territory - as the most suitable for an operational local public administration in order to guarantee the welfare and quality of life for the population-. The first step of the reform should be a review of the municipal attributions, capabilities and finances, establishing those that can be assigned to other administrations.
\end{abstract}

Keywords: municipality, municipal map, dysfunctions, municipal boundaries, local administration, Spain.

\section{[pt] O mapa municipal em Espanha: estrutura, evolução e problemáticas}

Resumo. O mapa municipal espanhol apresenta graves disfunções (sobrevivência dos pequenos municípios em população e em área; enclaves e problemáticos limites; poderes exagerados) produto de uma tradição que resiste à mudança. Depois de fazer uma análise da evolução e a estrutura atual da legislação

1 Universitat Autònoma de Barcelona, Departament de Geografia, 08193 Bellaterra

E-mail: abel.albet@uab.cat 
sobre a planta municipal e sobre a política de modificações, o texto denuncia as grandes dificuldades e a relutância de efetuar uma modificação do mapa municipal. A administração local é forçada a diferenciar o território "político" (campo da identidade e cidadania, mas reduto da influência dos partidos políticos), do território de "gestão", mais adequado para tornar operacional a administração pública local, garantindo o bem-estar e qualidade de vida para a população. A primeira etapa da reforma deve ser uma revisão das funções, competências e financiamento dos municípios, determinando as que podem ser atribuídos a outras administrações.

Palavras-chave: município; mapa municipal; disfunções; limites municipais; administração local; Espanha.

Sumario. Introducción. 1. Evolución de la estructura municipal contemporánea de España. 1.1. Institucionalización del municipio. 1.2. La lenta y problemática consolidación del régimen municipal. 1.3. La historia más inmediata. 2. La legislación sobre alteraciones municipales: evolución histórica. 2.1. Los primeros intentos de revisión del mapa municipal. 2.2. La legislación franquista sobre alteraciones municipales. 3. El mapa municipal: valoración de un legado. 3.1. El vacío legislativo en torno a los planes y políticas de alteración municipal. 3.2. Problemáticas territoriales de una evolución sin planificación. 3.3. Las disfuncionalidades en la toponimia. 4. El marco legal vigente en relación con el hecho municipal. 4.1. El municipio en la legislación hoy vigente. 4.2. Competencias y atribuciones de la administración local. 5. La legislación vigente sobre alteraciones de términos municipales. 5.1. El marco legal. 5.2. Posibilidades de alteración de los términos municipales. 5.3. Procedimiento legal de las alteraciones. 5.4. Políticas de alteración. 5.5. La legislación vigente: entidades locales. 6. Principales disfuncionalidades en el mapa municipal actual. 6.1. Pervivencia de los pequeños municipios. 6.2. Los enclaves y los límites municipales con formas caprichosas. 6.3. Problemáticas en la transgresión de límites municipales. 6.4. Cuestiones de toponimia. Algunas reflexiones finales. Bibliografía.

Cómo citar: Albet i Mas, Abel (2019) “El mapa municipal en España: estructura, evolución y problemáticas”. Geopolítica(s). Revista de estudios sobre espacio y poder, vol. 10, núm. 1, 11-40.

(...) pero los límites de los departamentos, distritos y municipios, a menudo son igualmente artificiales, y también acabarán por borrarse, pero cuando ya habrán provocado la rotura de numerosas comunicaciones naturales y habrán entorpecido de mil maneras el movimiento espontáneo de la gente. (...) Y si las fronteras estatales dependen de la voluntad de

los pueblos y deben ser modificadas conforme a sus deseos, lo mismo puede aplicarse a las fronteras igualmente convencionales, que separan artificialmente los Estados en diferentes provincias y municipios. (...) Es un verdadero contrasentido pretender que, a través de lineas inmutables, se fije una historia que se modifica y transforma constantemente. Eliseo Reclus, geógrafo y anarquista (1830-1905)

\section{Introducción}

"Son los hombres los que hacen las monarquías y las repúblicas, pero el municipio parece venir de Dios": esta significativa afirmación de Alexis de Tocqueville refleja a la perfección la visión que, sobre la realidad municipal, tradicionalmente se ha venido manteniendo en España y que, muy a menudo, todavía parece vigente. El municipio es, ciertamente, una estructura básica de la convivencia y la organización social, dibujada sobre un espacio geográfico muy concreto y diferenciado y con el que los habitantes sostienen una directa identificación. Sus orígenes ancestrales y los 
firmes y concluyentes lazos existentes entre sus elementos característicos (territorio, población y organización sociopolítica), confieren al municipio aquella aureola de eternidad, invulnerabilidad y autolegitimación casi "divina" citada por Tocqueville.

$\mathrm{Ni}$ siquiera los organismos europeos especializados (como el Consejo de los $\mathrm{Mu}$ nicipios y las Regiones Europeas ${ }^{2}$ ) se ponen de acuerdo en relación a qué modelo de mapa municipal funciona mejor: si el británico (solo 466 municipios, con un promedio de 144.000 habitantes cada uno, pero divididos en más de 12.000 parroquias) o el francés (cerca de 37.000 municipios) ${ }^{3}$. Tampoco hay consenso acerca de los procedimientos de intervención en dicho mapa pero es una realidad que, desde 1945, gran parte de los países europeos han reducido drásticamente el número de sus municipios (Tabla 1).

Tabla 1. Reducción de municipios en ciertos países europeos

\begin{tabular}{|l|r|r|c|}
\hline país / año & 1950 & 2015 & \% de reducción \\
\hline Dinamarca & 1.387 & 98 & 92,9 \\
\hline Bulgaria & 2.178 & 255 & 88,3 \\
\hline Suecia & 2.282 & 286 & 87,5 \\
\hline Escocia & 432 & 65 & 85,0 \\
\hline Gales & 168 & 37 & 78,0 \\
\hline Bélgica & 2.669 & 589 & 77,9 \\
\hline Inglaterra & 1.244 & 332 & 73,3 \\
\hline Grecia & 940 & 325 & 65,4 \\
\hline Alemania & 24.018 & 8.514 & 64,6 \\
\hline Noruega & 744 & 443 & 40,5 \\
\hline Austria & 3.879 & 2.357 & 39,2 \\
\hline Países Bajos & 1.014 & 647 & 36,2 \\
\hline España & 9.212 & 8.120 & 11,9 \\
\hline Francia & 37.874 & 36.682 & 3,1 \\
\hline
\end{tabular}

Fuente: elaboración propia.

En especial, en los últimos 15 años se han llevado a cabo fusiones incentivadas (Finlandia, Islandia, Noruega, Países Bajos) o forzadas (Alemania [Meligrana, 2004], Suecia [Durán, 2016: 96], Turquía). Desde el estallido de la crisis de 2007, otros países han ido aplicando la receta de las fusiones para cumplir con los objetivos de déficit marcados por la UE: Dinamarca, Grecia ${ }^{4}$, Portugal... En otros casos, como

2 El Council of European Municipalities and Regions (CEMR) es la más antigua asociación europea de gobiernos locales y regionales; en ella confluyen municipios y entidades regionales de 42 países europeos [http://www.ccre.org].

3 Con todo, las directrices del Consejo de Europa fijan en 10.400 el umbral de vecinos por ayuntamiento que garantizaría la existencia de unas finanzas locales saneadas.

4 Con la excusa de solventar la crisis económica, la intervención de la "Troika" en la organización social y en la política institucional de Grecia llevó a una profunda y dura reestructuración, a través del llamado "Plan Calícatres" (2010) que, entre algunos de sus aspectos básicos, establecía la supresión de los municipios de menos de 25.000 habitantes en la zona metropolitana de Atenas y de menos de 10.000 en el resto del país, exceptuando las zonas más montañosas, en las que el límite se quedó en 2.000. La aplicación del plan supuso (a través de fusiones voluntarias o forzadas) pasar de 940 municipios a 325. Si este criterio se aplicase a España, solo pasarían el corte 759 municipios: los demás (7.357) deberían reestructurarse para una mejor racionalización y búsqueda de eficiencia. La posible aplicación de un "Plan Calícrates" para España ha sido considerada como una posibilidad y una oportunidad (Font \& Galán, 2012a; Izu, 2011). 
Francia o Chipre, se ha apostado por la cooperación intermunicipal, sin acudir a fusiones o agregaciones.

En España, donde la ciudadanía mantiene un fuerte arraigo hacia sus entidades locales y regionales, las reformas de adelgazamiento o racionalización territorial son muy difíciles de llevar a cabo (Gómez Mendoza \& García Álvarez, 2001). No debe extrañar que a menudo cualquier simple propuesta de modificación (y más si se trata de supresión) en el status de un municipio implique grandes reticencias por parte de los ciudadanos: las reacciones abarcan desde el trauma sentimental hasta la revuelta exaltada. Dos ejemplos pueden dar la medida de la trascendencia del municipio en la sociedad española: la Ley de Administración Local de Aragón aprobada en abril de 1999 reconoce en su artículo 4 que "renuncia a poner en marcha una remodelación del mapa municipal, dada la dificultad de plasmarla en su texto y lo delicado del tema por el rechazo que la personalidad propia genera en las colectividades afectadas" . En febrero de 2001 se hizo público el informe, no vinculante, que un grupo pluridisciplinar y multipartidista de expertos había elaborado por encargo del Parlamento de Cataluña; el encargo hacía referencia a la revisión del mapa comarcal pero paralelamente en el informe se remarcaba la necesidad de hacer cumplir la legislación vigente y propiciar la fusión y mancomunación de municipios (Comissió d'Experts, 2000). El clamor del rechazo social y ciudadano llegó prácticamente hasta el insulto personal.

Así pues, en España los ciudadanos ven en el municipio el más íntimo territorio político y de identidad, así como parte de su voz en la sociedad. Paralelamente, se sigue concibiendo el municipio como una entidad estrictamente administrativa y que mantiene como finalidad básica la prestación de una serie de servicios cada vez más complejos. El elevado coste de muchos de estos servicios y el progresivo empobrecimiento de muchos municipios rurales (debido a los ritmos demográficos y económicos que provocan la decadencia de estas zonas) inciden aún más negativamente en dichos municipios de escasa entidad y faltos de recursos, dejando a los vecinos desatendidos de unos servicios, bienestar y oportunidades que se supone que son un derecho de todos los ciudadanos sin importar su lugar de residencia, pero que en la práctica se convierten en ventajas comparativas para los que viven en municipios grandes o en áreas urbanas.

Junto a ello, el desmantelamiento de los organismos metropolitanos que caracteriza los recientes procesos de desregulación deja en evidencia los ya absurdos límites municipales dentro de las grandes conurbaciones españolas, a la vez que se impide la óptima gestión de las múltiples problemáticas de estas áreas (Arias, 1980).

\section{Evolución de la estructura municipal contemporánea de España}

\subsection{Institucionalización del municipio}

En España la estructura municipal contemporánea empieza, de hecho, con los planteamientos liberales del Decreto de 23 de mayo de 1812 donde se reconoce el

5 En 1986 llegó a celebrarse un Congreso "en defensa del pequeño municipio" (ACM, 1986). 
municipio como una entidad natural e individualizada ante la ley creándose el marco para que se constituyan ayuntamientos en muchas localidades.

Previa a esta legislación, la organización local se distinguía por la más absoluta diversidad, producto de la estructura política, social, económica y jurídica del Antiguo Régimen y a menudo herencia de prerrogativas medievales, pueblos sin ningún tipo de organización subsistían juntamente con ciudades con representación en las Cortes; ayuntamientos constituidos existían paralelamente a dominios nobiliarios cuyos señores mantenían el derecho de designar los cargos municipales (Morell, 1972: 52; Burgueño \& Gras, 2014).

Así, el principio de igualdad importado desde la Francia revolucionaria (que había creado más de 40.000 entidades municipales por todo el país partiendo del principio de equiparación de todos los ciudadanos ante la Ley), lleva a considerar que en España todo núcleo a partir de 1.000 habitantes debería constituirse en ayuntamiento, si bien agrupaciones menores reciben igualmente todo tipo de facilidades para poder hacerlo (incluso núcleos de 100 habitantes, y todavía menores, cuando "otras razones de bien público" así parecen aconsejarlo) (Liesa, 1972: 23). Esta voluntad de generalización del municipio en base a criterios de racionalización y homogeneización es un claro exponente de la tendencia liberal de abolir todo tipo de privilegios y favorecer la formación de un mercado en base a criterios político-económicos modernos.

\subsection{La lenta y problemática consolidación del régimen municipal}

Esta vocación municipalista tiene una continuidad muy imprecisa a lo largo de todo el siglo XIX y buena parte del XX: entre 1812 y 1931 la legislación básica referente a la organización municipal de España es alterada más de 20 veces, con sucesivas aprobaciones y derogaciones de leyes y la redacción de otras 20 que no pasan de ser proyectos de ley. Ello no es sino reflejo de la inestabilidad política y de la alternancia de gobiernos absolutistas, liberales y conservadores que caracteriza la España de la época, pero también es exponente de la importancia concedida al régimen local (García, 1983).

Es durante el Directorio Militar del General Primo de Rivera cuando se aprueba, el 8 de marzo de 1924, el "Estatuto Municipal". Ideológicamente este Estatuto no sostiene muchas afinidades con la Dictadura que le da vigencia, sino que cabe entenderlo como una fórmula refundida de la experiencia de tantos proyectos anteriores abortados o insuficientes. Se trata de un texto técnica y conceptualmente avanzado (e incluso progresista) que reconoce el municipio no como el producto exclusivo de una ley sino como un hecho social de convivencia, anterior al Estado e incluso superior a la misma Ley. Ante el evidente desfase entre los postulados teóricos del Estatuto Municipal y los principios políticos del Directorio Militar, muy pocos artículos llegaron a tener una aplicación práctica (Tusell \& Chacón, 1973).

Según la Constitución Republicana promulgada en 1931, la potestad legislativa del nuevo régimen queda compartida entre el Estado central y las regiones autónomas, allí donde estén constituidas: gracias a esta posibilidad, en agosto de 1933 se aprueba la Ley Municipal de Cataluña (LMC), casi dos años antes (julio de 1935) que la Ley de Bases del Régimen Local (LBRL) de ámbito español. En esta Ley de Bases se reconoce la plena autonomía de los municipios a pesar de que el alcalde, 
además de Presidente del Ayuntamiento, mantiene la condición de representante de la Administración del Estado en el término municipal.

\subsection{La historia más inmediata}

Ya durante la Guerra Civil (1936-39), y como consecuencia de la revolución de julio de 1936, muchos municipios urbanos y rurales se organizaron en forma comunal a partir de principios socialistas, comunistas y anarquistas propugnados por dirigentes obreros y campesinos que asumieron la administración y la gestión de numerosos ayuntamientos. A pesar de la situación de excepcionalidad dictada por el conflicto bélico, la experiencia alternativa de gobierno revolucionario puede considerarse extremadamente exitosa.

Contrariamente, la facción rebelde del ejército republicano comandada por el General Franco crea, en las localidades bajo su control, unas "comisiones gestoras" que sustituyen a los ayuntamientos democráticamente constituidos y que son integradas por personalidades de la vida local adictas al nuevo orden. Una vez finalizada la guerra, diversos decretos y leyes, que culminarán en la Ley Orgánica de Bases del Régimen Local (LOBRL) de 1945 y el Texto Refundido de 1955, alejarán de los ayuntamientos cualquier forma de representatividad democrática. El régimen autoritario justificó la designación directa y la duración indefinida de los cargos públicos por el hecho de ostentar la representación del Estado en el municipio.

\section{La legislación sobre alteraciones municipales: evolución histórica}

\subsection{Los primeros intentos de revisión del mapa municipal}

Aunque de forma extremadamente tímida, es en una Ley de 1845 cuando se establece una primera medida de corrección del mapa municipal español al proponer que todos los municipios de menos de 30 habitantes deberían desaparecer. Este umbral mínimo aumenta a 50 habitantes en una ley de 1856 y a 200 en otra de 1866; en todos los casos se trata de medidas orientativas y nunca obligatorias. La Ley Municipal de 1877 constata la problemática generada por el rápido crecimiento de las grandes ciudades y abre la posibilidad de agregar al municipio de Madrid y a las ciudades de más de 100.000 habitantes, todas las localidades y municipios que se encuentren a menos de 10 y $6 \mathrm{~km}$., respectivamente (DGCL, 2008).

No es hasta el ya citado Estatuto Municipal de 1924 cuan empieza a haber una normativa precisa y a distinguirse claramente entre los conceptos de constitución, fusión, y alteración de municipios: en cualquiera de los casos, el Estatuto exige la conformidad de la mayoría de los vecinos implicados y de los dos tercios de los concejales de los respectivos ayuntamientos. En caso de segregación, la ley prevé que esta no puede afectar en detrimento de la riqueza y vida autónomas de las partes implicadas. Cualquier alteración exige, exclusivamente, el acuerdo de las partes implicadas y la comunicación al Gobernador Civil de la provincia: ello es prueba del reconocimiento otorgado por este Estatuto a la soberanía municipal, sin menoscabo de que por "intereses generales" (incorporación de municipios a ciudades de más de 
100.000 habitantes, agrupación forzosa de municipios con menos de 2.000 habitantes, etc.) también pueda intervenir el gobierno central (Melón, 1954, 1977).

La Ley Municipal de Cataluña (en vigor desde 1934) distingue ya diversas posibilidades de alteración de límites municipales: por agregación o segregación parcial de un municipio hacia otro vecino, por segregación parcial de uno o más municipios y así formar uno de nuevo, etc. (Burgueño \& Lasso de la Vega, 2002). La única medida correctora es la que impone la obligatoriedad de la asociación entre municipios en los que el salario del secretario del ayuntamiento sea superior al $20 \%$ del presupuesto ordinario. Posteriormente, la Ley Municipal española crea una detallada tipología de posibles modificaciones de términos remarcando, en cada caso, los requerimientos mínimos y los trámites precisos para llevarlas a cabo.

\subsection{La legislación franquista sobre alteraciones municipales}

La legislación franquista sobre alteraciones de términos municipales se basa en diversos reglamentos, como el de Población y Demarcación Territorial de 1952, que desarrollan lo que se decía en la Ley de Bases y el Texto Refundido. Si bien es de difícil interpretación, de dicha legislación se desprenden cuatro posibilidades de alteración municipal: por incorporación de uno o diversos municipios a otro (u otros), por fusión de dos o más municipios vecinos, por segregación parcial de uno o más municipios para constituir otro independiente, o por segregación parcial de un municipio para agregarlo a uno de contiguo.

También en caso de expansión y confusión de los núcleos urbanos, los municipios pueden iniciar trámites de fusión, si bien en la práctica esta posibilidad sería aplicada casi exclusivamente al caso de Madrid por claras razones políticas y de magnificación de la capital, a la vez que se ponían impedimentos a que esto mismo sucediese en Barcelona donde este tipo de disfunción era (y es) realmente problemática (Nadal, 1985).

Los trámites podían ser iniciados tanto por parte de los ayuntamientos interesados como por el gobierno central, así como las diputaciones y gobiernos civiles provinciales, si bien la decisión final correspondía siempre al Consejo de Ministros. En el caso óptimo de que los informes preceptivos para formalizar y justificar las iniciativas y las decisiones llegasen a elaborarse, a menudo no tenían la más mínima objetividad.

\section{El mapa municipal: valoración de un legado}

\subsection{El vacío legislativo en torno a los planes y políticas de alteración municipal}

Si bien es cierto que entre 1815 y 1860 el número total de municipios en España disminuye considerablemente, ello no es producto de una planificación precisa sino más bien de un lógico ajuste del tramado municipal recientemente instaurado. Esta revisión no tiene una continuidad definida, por lo que no es exagerado afirmar que a principios del siglo XXI la configuración municipal de España sigue siendo, fundamentalmente, la misma que a principios del siglo XIX. 
A pesar de esta tendencia, cabe reconocer que la década de 1960, y ante los cambios socioeconómicos experimentados por el conjunto del país, se caracteriza por un gran número de fusiones y agregaciones de municipios (Tabla 2), incentivadas en parte por una Ley de 1966 (la excepción en medio del desierto legislativo sobre el tema) que propicia ciertas subvenciones y exacciones fiscales dirigidas a "agrupaciones de municipios" o a entidades que decidan su fusión o incorporación. Bajo la consigna de inmediata y sistemática reducción en el número absoluto de municipios y con la promesa de mejoras estructurales, muchos pequeños municipios fueron presionados a "desaparecer del mapa".

Tabla 2. Evolución del número total de municipios

\begin{tabular}{|c|c|c|c|c|c|c|c|c|c|c|c|c|c|}
\hline $\begin{array}{l}\text { Comunidad } \\
\text { autónoma / } \\
\text { Año }\end{array}$ & 1900 & 1910 & 1920 & 1930 & 1940 & 1950 & 1960 & 1970 & 1980 & 1990 & 2000 & 2010 & 2018 \\
\hline Andalucía & 801 & 800 & 802 & 799 & 804 & 799 & 799 & 796 & 760 & 767 & 769 & 770 & 778 \\
\hline Aragón & 947 & 947 & 946 & 944 & 942 & 935 & 935 & 820 & 725 & 729 & 730 & 731 & 731 \\
\hline Asturias & 79 & 79 & 79 & 78 & 78 & 78 & 78 & 78 & 78 & 78 & 78 & 78 & 78 \\
\hline Canarias & 90 & 90 & 91 & 90 & 89 & 88 & 87 & 87 & 87 & 87 & 87 & 88 & 88 \\
\hline Cantabria & 102 & 102 & 102 & 102 & 102 & 102 & 102 & 102 & 102 & 102 & 102 & 102 & 102 \\
\hline $\begin{array}{l}\text { Castilla y } \\
\text { León }\end{array}$ & 2.809 & 2.806 & 2.805 & 2.811 & 2.808 & 2.803 & 2.797 & 2.572 & 2.251 & 2.247 & 2.249 & 2.248 & 2.248 \\
\hline $\begin{array}{l}\text { Castilla-La } \\
\text { Mancha }\end{array}$ & 1.071 & 1.071 & 1.072 & 1.088 & 1.087 & 1.086 & 1.085 & 1.004 & 912 & 915 & 919 & 919 & 919 \\
\hline Cataluña & 1.075 & 1.073 & 1.070 & 1.062 & 1.064 & 1.059 & 1.059 & 976 & 936 & 942 & 946 & 946 & 947 \\
\hline $\begin{array}{l}\text { Com. Va- } \\
\text { lenciana }\end{array}$ & 540 & 542 & 541 & 545 & 545 & 545 & 547 & 545 & 534 & 538 & 541 & 542 & 542 \\
\hline $\begin{array}{l}\text { Extrema- } \\
\text { dura }\end{array}$ & 384 & 383 & 383 & 388 & 386 & 385 & 385 & 381 & 380 & 380 & 383 & 385 & 388 \\
\hline Galicia & 323 & 322 & 319 & 319 & 319 & 316 & 315 & 312 & 312 & 313 & 315 & 315 & 313 \\
\hline $\begin{array}{l}\text { Islas Ba- } \\
\text { leares }\end{array}$ & 61 & 62 & 61 & 65 & 65 & 65 & 65 & 65 & 65 & 67 & 67 & 67 & 67 \\
\hline La Rioja & 184 & 183 & 183 & 183 & 182 & 183 & 184 & 183 & 174 & 174 & 174 & 174 & 174 \\
\hline Madrid & 195 & 195 & 195 & 196 & 196 & 184 & 183 & 183 & 176 & 178 & 179 & 179 & 179 \\
\hline Murcia & 42 & 42 & 42 & 42 & 42 & 42 & 43 & 43 & 43 & 44 & 45 & 45 & 45 \\
\hline Navarra & 269 & 269 & 269 & 267 & 266 & 265 & 265 & 265 & 264 & 265 & 273 & 272 & 272 \\
\hline País Vasco & 294 & 295 & 295 & 281 & 280 & 275 & 271 & 241 & 226 & 245 & 250 & 251 & 251 \\
\hline $\begin{array}{l}\text { Ceuta y } \\
\text { Melilla }\end{array}$ & 2 & 2 & 2 & 2 & 2 & 2 & 2 & 2 & 2 & 2 & 2 & 2 & 2 \\
\hline España & 9.268 & 9.263 & 9.257 & 9.262 & 9.256 & 9.212 & 9.202 & 8.655 & 8.027 & 8.073 & 8.109 & 8.114 & 8.124 \\
\hline
\end{tabular}

Fuente: Variaciones de los municipios de España desde 1842. Madrid: Ministerio de Administraciones Públicas, D.G. Cooperación Local 
En 1977 esta política de incentivos se abandona definitivamente y, con ella, se fulmina el único (a pesar de que inoperante e insuficientemente utilizado) aliciente a la integración entre entes locales: si bien entre 1966 y 1976 en el conjunto de España desaparecen 1.025 municipios (Sosa \& de Miguel, 1987: 55) cabe tener presente que sólo en muy contadas ocasiones las modificaciones fueron consecuencia directa de aquellos incentivos legales. De la misma forma, hay que relativizar el éxito y las consecuencias de este canal legislativo al constatar el hecho de que muchos de los municipios fusionados volverían poco más tarde a ser independientes (Perdigó, 1987).

\subsection{Problemáticas territoriales de una evolución sin planificación}

Todas las alteraciones ocurridas en los últimos 50 años no responden a ninguna política global concreta ni a ninguna planificación u ordenación territorial sino a la única directriz, emanada desde el ministerio correspondiente y ejecutada por las respectivas diputaciones y gobiernos civiles, de reducir sistemáticamente el número total de municipios. Las modificaciones se llevan a cabo allí donde la iniciativa y los intereses locales (particulares o públicos) adquieren suficiente consistencia e insistencia como para ser atendidos por la administración o bien, justo al contrario, donde la población y las fuerzas sociales locales no tienen suficiente poder como para reaccionar a anexiones impuestas: este puede ser el caso de numerosos municipios de alta montaña, fusionados casi siempre de forma arbitraria y provocando, pues, graves disfuncionalidades que se añaden a las que anteriormente ya mantenían (Arqué, García \& Mateu, 1979).

Es en base a este hecho que puede entenderse más fácilmente la gran cantidad de municipios desaparecidos en esa época a iniciativa de las diputaciones provinciales de Soria, Segovia, Huesca, Guadalajara, Cuenca o Burgos ${ }^{6}$. En Cataluña se dispone de la experiencia de la Diputación de Lleida que bajo la iniciativa de su presidente y del jefe provincial de administración local realizó, entre fines de los años 1960 y principios de los 1970, un proceso sistemático de reducción del número de municipios leridanos: el paso de 320, en 1961, a 245, en 1971, es considerado por parte de los responsables de la administración local de la provincia de Lérida de la época como "un gran éxito y un gran paso hacia la modernidad" (Liesa, 1972: 3)

A pesar de la imperiosa necesidad de resolver la excesiva fragmentación y la existencia de muchos municipios con escasa población y recursos, la solución adoptada fue la de la agregación (y, pues, desaparición) de muchos municipios a otros, con el simple objetivo de economizar tanto estructuras administrativas y de gestión como infraestructuras y servicios, sin buscar la coherencia de los nuevos conjuntos municipales. Se erradicó así, de golpe, buena parte de la herencia histórica de muchos lugares, privando a los habitantes de un canal de participación y gestión directa,

6 Existe un considerable número de textos que, publicados en este periodo, reflejan la dimensión y las repercusiones de este proceso: INE (1981); García Pascual (1960); Gallego (1955); López Vila (1969); Martín-Retortillo (1961); Jordana de Pozas (1961); Díez (1966); Lara (1966); Martín (1964); Melón (1974), y Villegas (1973).

7 Burgueño (2004: 10-19) presenta un extenso y detallado análisis acerca de los proyectos de reforma municipal entre 1960 y 1977. 
ya que en muy pocas ocasiones los municipios desaparecidos se convirtieron en entidades menores.

La perspectiva histórica ha bien demostrado cómo, muchas veces, estos procesos afectaron gravemente el carácter y la conciencia específica de pueblos, municipios y valles, e incluso la coherencia comarcal. En el Alto Pirineo, por ejemplo, buena parte de las agregaciones se hicieron con criterios de funcionalidad equivocados, municipios vecinos podían ser obligados a fusionarse sólo por el hecho de ser contiguos sin contemplar las posibles afinidades de las respectivas fuentes de recursos económicos, la orografía y las características de la accesibilidad interna, las tradiciones y las relaciones humanas, etc. formándose así entidades municipales artificiosas e incluso claramente absurdas (Mateu, 1988: 34-40).

\subsection{Las disfuncionalidades en la toponimia}

Como una repercusión más de aquella falta de sensibilidad por parte de cualquier estamento de gobierno y, evidentemente, debido a la larga situación de anormalidad que las lenguas y las culturas catalana, vasca y gallega sufrieron durante el franquismo, también la toponimia local fue maltratada. Así, además de la españolización de numerosos topónimos, la alteración de términos municipales implicó a veces la aparición de nueva toponimia. En ocasiones, a pesar de no mantener una notable tradición, se trató de nombres coherentes con el territorio que representaban, sin embargo, en algunos lugares se detectaron significativas incorrecciones e incluso construcciones artificiosas: el caso quizá más aberrante se dio en Cataluña donde FORALLAC resultó la extraña combinación de sílabas procedentes de los topónimos de los tres municipios que en su día se fusionaron: FOnteta, PeRAtallada, VulpeLLAC (Rueda, Camarasa \& Mateu, 1987).

\section{El marco legal vigente en relación con el hecho municipal}

El cambio político iniciado en 1976 en España, que tiene su momento estelar en 1977 (con la legalización de los partidos políticos y las primeras elecciones generales) y en 1978 (aprobación de la Constitución e inicio del proceso autonómico), no afecta las instituciones locales hasta 1979, con la celebración de las elecciones municipales y la constitución de los primeros ayuntamientos y diputaciones democráticos desde 1939 (Orduña, 2003).

\subsection{El municipio en la legislación hoy vigente}

La Constitución española de 1978 reconoce el nivel local como una de las tres esferas de poder (junto con la estatal y la de las comunidades autónomas) en que el país se organiza, pero no define que la normativa del régimen local sea competencia exclusiva del estado central o de las respectivas autonomías, sino que se reparte entre ambos. Así, a la legislación estatal (prioritaria) se sobrepone la que, eventualmente, algunas comunidades autónomas hayan podido legislar. En este sentido, el Estado central se reserva el derecho de dictaminar las bases del régimen jurídico de las Administraciones Públicas mientras que las comunidades autónomas asumen 
competencias sobre las alteraciones de los términos municipales integrados en su propio territorio y, en general, las funciones que correspondan a la Administración del Estado sobre las corporaciones locales.

En este sentido, la Ley Reguladora de las Bases de Régimen Local (de 2 de abril de 1985) vino a ser no sólo el marco genérico en el que se inspira el resto de la legislación estatal sobre los aspectos locales sino el punto de obligada referencia de las normativas particulares desarrolladas por algunas comunidades autónomas ${ }^{8}$. Así, la Ley de Bases reconoce como entidades locales el municipio, la provincia y, en su caso, la isla, así como, eventualmente, las entidades locales menores, las comarcas, las áreas metropolitanas, y las mancomunidades; a todas estas entidades se les reconoce, además de la plena autonomía, la potestad reglamentaria, de auto-organización tributaria y financiera, de planificación, de expropiación, de ejecución y sanción, etc. con plena legitimidad y ejecutividad de sus actos.

Paralelamente, el municipio es también reconocido como la entidad básica de la organización territorial del Estado, siendo definido por su territorio, su población, y su organización. La Ley refleja los derechos y los deberes de los vecinos, así como la organización, administración y gobierno de los municipios con sus atribuciones y competencias mínimas. Los aspectos de tipo territorial y demográfico son tratados de forma detallada en el Real Decreto de 11 de julio de 1986, por el cual el Estado central aprobó el Reglamento de Población y Demarcación Territorial de las Entidades Locales.

Cataluña (1987), Murcia (1988), Navarra (1990), Castilla-la Mancha (1991), Andalucía (1993), La Rioja (1993), o Aragón (1999) son algunas de las comunidades autónomas que han legislado sobre la administración local municipal mientras que Asturias, Baleares, Cantabria, Castilla y León, Extremadura, Galicia y País Vasco tienen algún tipo de ley o decreto referente a mancomunidades o entidades locales menores. Quizá el caso de Cataluña es de los más ejemplares y completos ya que el 15 de abril de 1987 aprueba su propia Ley Municipal y de Régimen Local que desarrolla al máximo todas las atribuciones que su Estatuto de Autonomía y la Ley de Bases del estado central le confieren ${ }^{9}$. Además, por un Decreto de 24 de mayo de 1988, la Generalitat de Cataluña aprueba su Reglamento de Demarcación Territorial y Población de los Entes Locales, regulando de forma muy concreta (incluso con mayor precisión que el reglamento correspondiente de la administración central), los

8 El 27 de diciembre de 2013 se aprobó la Ley 27/2013 de Racionalización y Sostenibilidad de la Administración Local (LRSAL) que retocaba ligeramente parte del articulado de la citada Ley de Bases de 1985: el preámbulo de la LRSAL argumenta, como razones de dicha modificación, tanto la reforma del artículo 135 de la Constitución realizada en 2011 (que consagraba la estabilidad presupuestaria como principio rector de las actuaciones de todas las Administraciones Públicas), como la necesidad de clarificar las competencias locales evitando solapamientos y disfuncionalidades entre el modelo competencial y las haciendas locales. A pesar de que las directrices de la LRSAL se convierten en el nuevo marco legal de referencia, las cuestiones relacionadas con el mapa municipal prácticamente no se ven alteradas. Con la excepción del Partido Popular, el resto de formaciones políticas españolas con representación parlamentaria se opusieron a la aprobación de esta Ley, argumentando que se trataba de un ataque a la autonomía municipal y de un instrumento para vaciar de contenido político los municipios pequeños en favor de una estrategia de privatización de los servicios públicos que pasarían a manos de las diputaciones provinciales.

9 En Cataluña, la aprobación de dicha Ley generó, antes y después, un amplio debate que queda recogido en Burgueño (2004: 23-28). Algunas de las principales referencias de dicho debate y sobre la posibilidad y la necesidad de una reforma del mapa municipal son: Casassas (1982-83, 1986); Casassas \& Clusa (1981); Ferret (1986); Mir (1991); Acadèmia de Jurisprudència (1984); Mateu (1989); Rueda, Camarasa \& Mateu (1987). 
rasgos esenciales del territorio, la denominación, los símbolos, y la población de los entes locales catalanes (Oliveras, 1997).

\subsection{Competencias y atribuciones de la administración local}

De acuerdo con los principios de eficacia, descentralización, desconcentración, coordinación y participación, los entes locales deben servir con objetividad a los intereses públicos que les son atribuidos, ejerciéndolos con plena autonomía, personalidad y responsabilidad jurídica. En este sentido la Ley prevé que todos los municipios además de las decisiones sobre sus términos municipales, su denominación, sus símbolos propios, su padrón, etc. son responsables de un largo listado de competencias "propias" en función de su número de habitantes, a la vez que pueden ejercer también ciertas actividades con carácter "complementario".

El articulado de la Ley prevé, ya de entrada, que algunos municipios deberán asociarse para ofrecer estos servicios (incluso los considerados imprescindibles para todos los municipios) y se establecen canales alternativos de prestación que les dispensen de aquella obligación primaria. Esta dispensa, entre otros motivos, puede ser concedida por razones de insuficiencia financiera, por la especial estructura del territorio y los asentamientos de población, por otras causas técnicas, o por suponer, dichas prestaciones, más del $50 \%$ del presupuesto anual.

Entrando en una clara contradicción, la misma Ley reconoce que la insuficiencia de medios económicos, materiales y personales para gestionar los servicios mínimos obligatorios es un argumento suficiente como para proceder a la agregación total o a la fusión del municipio afectado para integrarlo en otro y garantizar así la provisión del servicio previsto. Hasta el momento presente estas insuficiencias se han ido resolviendo gracias al papel de los consejos comarcales y de las diputaciones provinciales, tanto en lo que respecta a la asistencia a los municipios en los aspectos técnicos o financieros como de coordinación en la prestación y gestión de los servicios (Castells, 1983) ${ }^{10}$.

\section{La legislación vigente sobre alteraciones de términos municipales}

\subsection{EI marco legal}

Comenzando por la Ley Reguladora de las Bases del Régimen Local de 1985 y continuando por el desarrollo legislativo posterior, se parte siempre de la preexistencia y la aceptación de la herencia histórica que supone el tramado municipal. La inercia de la herencia de este tramado municipal considerado caso por caso o en conjunto, es realmente decisiva ya que a pesar de que las posibilidades de alteración ocupan un extenso capítulo en las leyes de régimen local actualmente vigentes, siempre se plantean en una aplicación restringida, a casos puntuales, y nunca cuestionando

10 En aras de una mayor racionalidad y sostenibilidad, la LRSAL de 2013 limita a los municipios y al resto de entidades locales su capacidad de asunción de competencias y servicios, exigiéndoles memorias económicas que avalen su disponibilidad y que avalen el cumplimiento de los principios de estabilidad, sostenibilidad financiera y eficiencia del servicio o la actividad (artículo 25.4) a la vez que reafirma a las diputaciones en su papel de garantes, coordinadoras, o implementadoras de determinados servicios (artículo 26.2). 
globalmente la totalidad del mapa municipal (Castelao, 1994; Perdigó, 1987; Díez, 2006; Durán, 2017).

Es cierto que un replanteamiento sistemático de la trama y el gobierno locales requeriría una voluntad política determinada y también un fondo legal diferente (más específico) que no el de una Ley de Bases, pero también es cierto que estos temas quedan siempre tan sólo vagamente apuntados: “... se podrán establecer medidas que tiendan a fomentar la fusión de municipios...” (cap. I, art. 13.3).

Sea como sea, la Ley de Bases expresa el objetivo genérico de conseguir el máximo número de fusiones entre municipios para poder "mejorar la capacidad de gestión de los asuntos públicos locales" (art. 13.3), si bien la falta de medidas prácticas (necesariamente de tipo económico) para incentivar este proceso supone la anulación fáctica de aquellos objetivos. A la vez se da la situación paradójica de que, a pesar de dicha intencionalidad global, en los últimos años los casos de segregación y creación de nuevos municipios son más numerosos que no los de fusión y agregación: ello es posible gracias a la inexistencia de medidas agregacionistas y la regresión de algunas fusiones contestadas por la ciudadanía, combinado con la progresiva resolución de múltiples casos conflictivos y en los que disfuncionalidades de muy diversa índole o bien agregaciones incoherentes realizadas en otras épocas, recomendaban ahora llevar a cabo iniciativas segregacionistas. Ni tan solo la aguda crisis económica y financiera sufrida por España desde 2007 ha servido para modificar la tendencia: entre 2007 y 2013 han surgido siete nuevos municipios y comparando el momento presente con mediados de la década de 1970, el número de municipios se ha incrementado en más de 70.

\subsection{Posibilidades de alteración de los términos municipales}

a) Agregaciones y fusiones. Para proceder a la agregación total de uno o diversos municipios en otro de limítrofe, la legislación española prevé las siguientes razones: 1) insuficiencia de medios económicos, materiales y/o personales para gestionar los servicios mínimos obligatorios, 2) que los núcleos de población formen un continuo urbano y 3) cuando otros aspectos de orden geográfico, demográfico, económico o administrativo así lo hagan necesario o, al menos, aconsejable. Ante los supuestos 2) y 3 ) es también posible realizar agregaciones parciales (o alteraciones que sólo afectan una parte del territorio municipal) siempre y cuando se garantice que después de la alteración el municipio o municipios afectados gozarán de recursos suficientes para prestar los servicios mínimos establecidos.

El procedimiento y supuestos descritos para los casos de agregación coinciden con los de fusión (siempre de municipios limítrofes), si bien en este caso todos los municipios implicados desaparecen como tales en régimen de igualdad para formar un municipio nuevo con personalidad, administración e incluso denominación completamente nuevas.

b) Segregaciones. La legislación española contempla dos posibles versiones de segregación municipal: por un lado, la que separa parte de uno o varios municipios para agregarse a otro y, por el otro las que la parte segregada se constituye en municipio independiente. La Ley Municipal exige que para que la creación de un municipio a partir de segregación pueda ser efectiva debe afectar a núcleos de población 
territorialmente diferenciados y que los municipios finalmente resultantes cuenten con territorios y recursos suficientes para el cumplimiento de las competencias municipales y sin disminución en la calidad de los servicios (en relación con la situación precedente). En cualquier caso, se requiere una justificación objetivamente valorada de la mejora que la nueva situación puede implicar (Barranco, 1993; SCOT, 1993). La LRSAL, en su artículo 13.2, deja claro, además, que los eventuales nuevos municipios deberán tener un mínimo de 5000 habitantes.

c) Alteraciones de términos y continuidad territorial. Si bien en ningún momento la legislación hace referencia expresa a la problemática que crean los enclaves, la racionalización de la organización territorial haría aconsejable una política que tendiese a la eliminación de estas "anomalías" a partir de las posibilidades de agregación que la misma Ley ofrece (Sosa \& de Miguel, 1987: 86). Esta posible "normalización" de las discontinuidades, a pesar de ser siempre deseable, no siempre es de fácil realización ya que, si bien en muchas ocasiones la cuestión podría ser resuelta a través de acuerdos y pactos compensatorios entre los municipios interesados, en otras se requiere un tratamiento muy delicado e incluso una ley específica al afectar a provincias o incluso comunidades autónomas distintas.

d) Cambios en la denominación y la capitalidad. La legislación vigente sitúa la capital del municipio en el núcleo de población donde tiene la sede el ayuntamiento: cualquier cambio requiere el voto favorable de dos tercios de los concejales. La modificación del nombre del municipio necesita un acuerdo similar, así como también la aprobación final del gobierno autónomo. Sin embargo, ante denominaciones confusas, con incorrecciones lingüísticas o que no se corresponden con la toponimia local, el Consejero de Gobernación de la correspondiente Comunidad Autónoma puede proponer a los ayuntamientos el cambio de su nombre, siempre con el acuerdo de las instituciones científicas especializadas: la legislación vigente admite que la toponimia oficial de un municipio puede ser, a todos los efectos, en castellano, en cualquier otra lengua oficial en cada comunidad autónoma, o en ambas lenguas a la vez.

\subsection{Procedimiento legal de las alteraciones}

La Ley Municipal de Cataluña reconoce que el expediente de alteración de un término municipal puede partir de la iniciativa del o de los ayuntamientos implicados, de los consejos comarcales interesados, del Departamento de Gobernación de la Generalitat de Cataluña ("de oficio"), o bien a petición de los vecinos (un $50 \%$ de los afectados). En cualquier caso, para iniciar el expediente se necesita la redacción de una memoria que justifique los motivos de la alteración, así como los informes de todos los estamentos involucrados, juntamente con el de la Comisión de Delimitación Territorial y el dictamen de la Comisión Jurídica Asesora.

Es significativo destacar que el gobierno de la Generalitat de Cataluña (que expresa siempre la resolución definitiva de cualquier expediente) debe aprobar, necesariamente, cualquier alteración de términos propuesta a iniciativa de los ayuntamientos o de los vecinos y en la cual el acuerdo sea unánime y sin la objeción de ningún otro organismo implicado. 
En lo que respecta al deslinde de los términos municipales, el Reglamento de Demarcación reconoce a los ayuntamientos la facultad de promover la delimitación y el amojonamiento de sus términos, comunicando los acuerdos a los municipios y propietarios de fincas afectadas, además, claro está, del Departamento de Gobernación de la Generalitat de Cataluña ${ }^{11}$.

La Comisión de Delimitación Territorial (en tanto que órgano de estudio, consulta y propuesta) es la encargada, a iniciativa propia o a petición del Consejero de Gobernación, de elaborar las propuestas de corrección de las problemáticas detectadas en relación con los deslindes, los enclaves, las disfuncionalidades causadas por infraestructuras o continuos urbanos, etc. Aunque en alguna ocasión implica largas negociaciones, al cabo del año se vienen aprobando numerosas adecuaciones de deslindes de este tipo ${ }^{12}$.

\subsection{Políticas de alteración}

Tanto en la genérica Ley de Bases como en el Reglamento de Población y Demarcación se insinúa (y, de hecho, queda en insinuación) la necesidad de llevar a cabo una política que fomente la agregación y fusión de municipios. Sin embargo, la Ley Municipal de Cataluña en sus artículos 20 y 21 no sólo hace suyo este precepto, sino que propone medidas concretas de estímulo a la agregación o fusión voluntaria entre municipios. Estas medidas tienen una vertiente en lo fundamental económica ya que prevén ayudas financieras y técnicas y tratos preferenciales en la realización de inversiones, además de otros posibles pactos o condiciones particulares establecidas entre los municipios, en el marco de la legislación del régimen local. La crisis económica y los recortes presupuestarios de la última década han contribuido decisivamente a no implementar dichas ayudas ni tan siquiera cuando estas se regulan de manera más explícita para toda España gracias a las propuestas de la LRSAL de 2013.

El Reglamento de Población y Demarcación parece más contundente ya que expone un listado de posibles causas concretas por las que se puede proceder a la agregación total de uno o diversos municipios, si bien alguno de los principios citados puede tener una aplicación difícil y comprometida. A pesar de ello, desde su aprobación se ha hecho caso omiso a esta legislación ya que, de implementarse, docenas de municipios se hubiesen visto inmediatamente cuestionados sólo por una de dichas causas: el hecho de estar habitados por menos de 250 personas.

Todas estas medidas tienden a propiciar las uniones voluntarias entre municipios; en caso de que el gobierno catalán las considerase insuficientes o inoperantes para conseguir un nivel homogéneo en la prestación de los servicios de competencia municipal, la Ley prevé la posibilidad de llevar a cabo, por parte de la Generalitat, un

11 El Instituto Geográfico Nacional (para el conjunto de España) y el Institut Cartogràfic i Geològic de Catalunya (para Cataluña) tienen una amplia capacidad técnica para trazar, verificar y resolver deslindes. Igualmente, existe una considerable bibliografía al respecto, que demuestra el interés en esta temática, tanto desde una perspectiva histórica o política como acerca de sus problemáticas técnicas; entre muchas otras referencias destacan: Albrich (2014); Capdevila (2005); Datzira (2012); Garrido-Villén et al. (2014); Hermosilla \& Rodrigo (1997); Masdeu, Jiménez \& Ledo (2015); Massó \& Torres (2009); Massó, Torres \& Jiménez (2011); Nadal \& Urteaga (2012), y Ticó \& García (1994).

12 En el caso de Cataluña, todos los casos y procedimientos de delimitación y deslinde están registrados en el portal web: http://municat.gencat.cat/ca/Temes/El-mapa-municipal/mapa_municipal/ 
proceso de agregaciones y/o fusiones forzadas en áreas restringidas o que por especiales circunstancias así parecieran requerirlo.

\subsection{La legislación vigente: entidades locales}

A pesar de que el municipio es la entidad más conocida, la Administración local es integrada por otros entes que tienen otras escalas de actuación (Tabla 3). La Secretaría de Estado para las Administraciones Territoriales es la encargada de realizar y mantener actualizado el Registro de Entidades Locales para el conjunto de España, integrado por municipios, comarcas, y provincias, así como por las entidades municipales descentralizadas, las mancomunidades de municipios, las entidades metropolitanas, y las agrupaciones de municipios (Subdirección..., 2009) ${ }^{13}$. Algunas Comunidades Autónomas mantienen, también, sus respectivos registros.

a) Entidades locales menores. Las entidades de ámbito territorial inferior al municipio ("EATIMEs" según el Registro de Entidades Locales del Ministerio de Hacienda y Administraciones Públicas, "Entidades municipales descentralizadas" según la terminología de la Ley Municipal de Cataluña) pueden constituirse en los núcleos de población que dentro de un municipio configuren una estructura de poblamiento separada y siempre y cuando su constitución no conlleve una pérdida de calidad en la prestación de los servicios generales del municipio, pueda contar con los recursos suficientes para llevar a cabo sus atribuciones o bien cuando se den circunstancias de orden geográfico, histórico, social, económico o administrativo que así lo requieran y, según la LRSAL de 2013, siempre y cuando resulten ser una opción más eficiente para la administración desconcentrada de núcleos de población separados. La iniciativa de constitución corresponde indistintamente a la mayoría de los vecinos interesados o al mismo ayuntamiento.

Aunque la LRSAL les elimina como entes con personalidad jurídica propia (artículo 24bis.1), es interesante remarcar que la Ley Municipal de Cataluña les reconoce la posibilidad de poseer un amplio abanico de competencias y atribuciones propias, que pueden llegar a ser todas las que gestionaría un municipio independiente, en caso de que la entidad en cuestión se haya formado a partir de la desaparición (por agregación o fusión) de un antiguo municipio. También es destacable la determinación de la Ley Municipal donde se prevé que la aprobación de la existencia de una entidad local menor implica la definición de los límites territoriales que abarca su jurisdicción: este hecho implica el mantenimiento de una singularidad, identidad y territorialidad bien definida y diferenciada a pesar de estar integrada en el ente y el territorio municipal global. Ello permite que la herencia histórica de un espacio y de una administración, así como la identidad de sus habitantes, no queden diluidos en una organización y un territorio más amplia a los que a menudo parece más difícil acceder y asumir como propios. En caso de agregaciones municipales, estas posibilidades deberían permitir superar muchas de las reticencias de los ciudadanos (Torres, 1985; Tort, 1993).

13 Dicho registro es accesible en el portal web: http://ssweb.seap.minhap.es/REL/frontend/inicio/municipios/all/all. 
b) Asociaciones de municipios: mancomunidades, áreas metropolitanas, consorcios y comarcas. Todas estas entidades son, de hecho, agrupaciones de municipios creadas para facilitar la provisión de uno o diversos servicios, así como para solventar ciertas problemáticas propias de ámbitos territoriales muy circunscritos, sin cuestionar la institución municipal (Martín, 1987).

A partir del acuerdo entre los municipios interesados, estos pueden asociarse en mancomunidades para ejecutar en común alguna obra o para la gestión de servicios de su competencia en los que una explotación colectiva resulta mucho más rentable y racional (Navarro, 2001) ${ }^{14}$.

La legislación permite también crear áreas metropolitanas cuyos objetivos son los de planificar, coordinar y gestionar aquellos servicios municipales que, por las características del ámbito conurbado donde se enmarcan, requieren una actuación supramunicipal. No obstante, y a diferencia de los municipios y comarcas de montaña, la Ley no define exactamente cuándo puede considerarse "metropolitana" una asociación de municipios. En las últimas décadas, razones políticas han relegado notablemente la figura del área metropolitana: son significativos los casos de Madrid (donde el territorio de la Comunidad Autónoma de Madrid coincide con uno de sus potenciales ámbitos metropolitanos) y de Barcelona (la Corporación Metropolitana de Barcelona fue desmembrada en 1987, cuando el gobierno de la Generalitat, entonces en manos del partido catalanista conservador, la consideró un contrapoder progresista excesivo).

De acuerdo con lo que establecen algunos estatutos de ciertas comunidades autónomas (Aragón, Asturias, Cataluña, Galicia), la comarca se constituye como una entidad local formada por la agrupación de municipios contiguos que tiene personalidad jurídica propia. En el caso de Cataluña, donde es la comarca (y no la provincia) la forma de organización territorial tradicional, además de prestar servicios públicos mínimos de alcance municipal o supramunicipal este ámbito puede convertirse en uno de los niveles de descentralización del gobierno autónomo. A diferencia de otras asociaciones de municipios, la organización comarcal se extiende por todo el territorio de la comunidad autónoma y ningún municipio puede quedar excluido ni pertenecer a más de una comarca. Se reconoce en las comarcas la existencia de una forma de gobierno propio (un presidente, un gerente, un consejo), con posibilidades de iniciativa legislativa ante el Parlamento; no obstante, la importancia del poder comarcal depende de la voluntad política del gobierno autónomo y, hasta la fecha, solo se les ha reconocido una función menor prestadora de ciertos servicios (Burgueño, 2001).

El caso de las veguerías es todavía más flagrante: el renovado Estatuto de Autonomía de Cataluña de 2006 reestableció este ámbito territorial histórico (de escala entre la comarca y el conjunto de Cataluña) como división territorial con personalidad jurídica propia y con dos funciones precisas: el gobierno intermunicipal de cooperación local (asumiendo buena parte de las competencias actuales de las

14 Un caso totalmente diferente es el de los territorios compartidos entre dos o más municipios y no atribuibles a uno solo: se trata, generalmente, de pastos o bosques, casi siempre sin población permanente que ocupan una situación intermedia o marginal en relación a dos pueblos o valles. Aunque muy menguados en relación con su notable extensión siglos atrás, siguen existiendo numerosos condominios de este tipo, que reciben diversas denominaciones según la región: terrenos comunales, cotos mancomunados, facerías, terme mitger, etc. (Burgueño \& Guerrero, 2014: 26-27; Burgueño \& Mòdol, 2016). 
diputaciones) y la organización de los servicios de la Generalitat de Cataluña. La falta de decisión política y los avatares de los últimos años han aparcado la implementación efectiva de dicho ámbito administrativo.

Tabla 3. Número de entidades locales (2018)

\begin{tabular}{|c|c|c|c|c|c|c|c|c|}
\hline $\begin{array}{l}\text { Comunidades } \\
\text { autónomas }\end{array}$ & (A) & (B) & (C) & (D) & (E) & $(F)$ & $(G)$ & $(H)$ \\
\hline Andalucía & 778 & 8 & 83 & 0 & 0 & 1 & 42 & 912 \\
\hline Aragón & 731 & 3 & 38 & 32 & 0 & 1 & 43 & 848 \\
\hline Asturias & 78 & 1 & 17 & 0 & 0 & 2 & 39 & 137 \\
\hline Canarias & 88 & 9 & 14 & 0 & 0 & 4 & 0 & 115 \\
\hline Cantabria & 102 & 1 & 22 & 0 & 0 & 0 & 521 & 646 \\
\hline Castilla y León & 2.248 & 9 & 241 & 1 & 0 & 24 & 2.223 & 4.746 \\
\hline Castilla-La Mancha & 919 & 5 & 126 & 0 & 0 & 2 & 42 & 1.094 \\
\hline Cataluña & 947 & 4 & 78 & 42 & 1 & 0 & 65 & 1.137 \\
\hline Com. Valenciana & 542 & 3 & 61 & 0 & 1 & 0 & 7 & 614 \\
\hline Extremadura & 388 & 2 & 58 & 0 & 0 & 4 & 21 & 473 \\
\hline Galicia & 313 & 4 & 38 & 0 & 0 & 0 & 9 & 364 \\
\hline Islas Baleares & 67 & 4 & 7 & 0 & 0 & 0 & 1 & 79 \\
\hline La Rioja & 174 & 1 & 29 & 0 & 0 & 0 & 4 & 208 \\
\hline Madrid & 179 & 1 & 54 & 0 & 0 & 0 & 2 & 236 \\
\hline Murcia & 45 & 1 & 8 & 0 & 0 & 0 & 0 & 54 \\
\hline Navarra & 272 & 1 & 61 & 0 & 0 & 3 & 346 & 683 \\
\hline País Vasco & 251 & 3 & 38 & 7 & 0 & 2 & 341 & 642 \\
\hline Ceuta y Melilla & 2 & 0 & 0 & 0 & 0 & 0 & 0 & 2 \\
\hline España & 8.124 & 60 & 973 & 82 & 2 & 43 & 3.706 & 12.990 \\
\hline $\begin{array}{l}\text { (A) Municipios } \\
\text { (B) Diputaciones pr } \\
\text { (C) Mancomunidade } \\
\text { (D) Comarcas } \\
\text { (E) Areas metropolit } \\
\text { (F) Otras asociacior } \\
\text { (G) Entidades locale } \\
\text { (H) Total de entidad }\end{array}$ & $\begin{array}{l}\text { as } \\
\text { munici } \\
\text { nenore } \\
\text { locales }\end{array}$ & $\begin{array}{l}\text { abildos } \\
\text { ios }\end{array}$ & sulares & & & & & \\
\hline
\end{tabular}

Fuente: Registro de entidades locales del Ministerio de Hacienda y Administraciones Públicas

\section{Principales disfuncionalidades en el mapa municipal actual}

Ante la ya repetida falta de planificación y de mínima previsión legislativa, a menudo la inexistencia de una adecuación coherente entre el término municipal heredado y la realidad de la vida local en constante evolución y desarrollo ha ido creando una serie de disfuncionalidades que, en ocasiones, dan pie a graves problemáticas ${ }^{15}$.

15 Guerrero \& Burgueño (2018) presentan un compendio de dichas disfuncionalidades que, aunque centrado en el caso de Cataluña, es perfectamente extrapolable al resto de España. 


\subsection{Pervivencia de los pequeños municipios}

No existe ningún criterio preestablecido para considerar como "pequeño" o "grande" a un municipio en función de su superficie. En el caso español, el promedio de superficie de los municipios (alrededor de $62 \mathrm{~km}^{2}$ ) tampoco es un dato significativo ya que su homogeneidad interna es escasa (Tabla 4). Así, cabe interpretar bajo ópticas muy distintas la existencia de una gran cantidad de municipios minúsculos en Castilla frente a los pequeños municipios de Cataluña, Aragón o del País Vasco. Como contraste a todos ellos, los extensísimos términos de Murcia, Andalucía o Extremadura se corresponden con la etapa final de la "Reconquista" y con un tipo de asentamiento concentrado debido a las características de la actividad económica allí desarrollada (Gavira, 1980: 35; Benito \& de la Vega, 2003; Torres, 1999).

Tabla 4. Número total de municipios según su superficie (2018)

\begin{tabular}{|c|c|c|c|c|c|c|c|c|}
\hline $\begin{array}{l}\text { Comunidades autó- } \\
\text { nomas }\end{array}$ & (A) & (B) & (C) & (D) & (E) & $(F)$ & (G) & (H) \\
\hline Andalucía & 778 & 13 & 112 & 207 & 182 & 201 & 63 & 112,6 \\
\hline Aragón & 731 & 14 & 133 & 281 & 175 & 112 & 16 & 65,3 \\
\hline Asturias & 78 & 0 & 3 & 15 & 25 & 27 & 8 & 135,9 \\
\hline Canarias & 88 & 0 & 7 & 36 & 16 & 26 & 3 & 84,6 \\
\hline Cantabria & 102 & 1 & 21 & 44 & 29 & 7 & 0 & 52,2 \\
\hline Castilla y León & 2.248 & 14 & 704 & 983 & 374 & 167 & 6 & 41,9 \\
\hline Castilla-La Mancha & 919 & 2 & 131 & 331 & 225 & 188 & 42 & 86,5 \\
\hline Cataluña & 947 & 39 & 384 & 335 & 138 & 50 & 1 & 33,9 \\
\hline Com. Valenciana & 542 & 79 & 169 & 148 & 89 & 51 & 6 & 42,9 \\
\hline Extremadura & 388 & 3 & 36 & 120 & 108 & 99 & 22 & 107,3 \\
\hline Galicia & 313 & 1 & 11 & 77 & 107 & 112 & 5 & 94,5 \\
\hline Islas Baleares & 67 & 0 & 12 & 22 & 15 & 17 & 1 & 74,5 \\
\hline La Rioja & 174 & 10 & 84 & 55 & 21 & 4 & 0 & 29,0 \\
\hline Madrid & 179 & 0 & 31 & 99 & 38 & 10 & 1 & 44,8 \\
\hline Murcia & 45 & 0 & 8 & 10 & 5 & 11 & 11 & 251,4 \\
\hline Navarra & 272 & 20 & 97 & 93 & 50 & 11 & 1 & 38,2 \\
\hline País Vasco & 251 & 23 & 121 & 72 & 24 & 11 & 0 & 28,8 \\
\hline Ceuta y Melilla & 2 & 0 & 2 & 0 & 0 & 0 & 0 & 15,4 \\
\hline España & 8.124 & 219 & 2.066 & 2.928 & 1.621 & 1.104 & 186 & 62,2 \\
\hline \multicolumn{9}{|c|}{$\begin{array}{l}\text { (A) Municipios } \\
\text { (B) Municipios de hasta } 5,00 \mathrm{~km} 2 \\
\text { (C) Municipios entre 5,01 y } 20,00 \mathrm{~km} 2 \\
\text { (D) Municipios entre 20,01 y } 50,00 \mathrm{~km} 2 \\
\text { (E) Municipios entre } 50,01 \text { y } 100,00 \mathrm{~km} 2 \\
\text { (F) Municipios entre } 100,01 \text { y } 300,00 \mathrm{~km} 2 \\
\text { (G) Municipios de más de } 300,00 \mathrm{~km} 2 \\
\text { (H) Promedio de la superficie municipal (km2) }\end{array}$} \\
\hline
\end{tabular}

Fuente: Registro de entidades locales del Ministerio de Hacienda y Administraciones Públicas

Atendiendo a la definición y clasificación de municipios en función de su número de habitantes (Tabla 5) la cuestión es todavía más compleja ya que en España existen diversas definiciones de municipio "pequeño" (desde considerar los menores de 
15.000 habitantes hasta los de menos de 1.000 habitantes) ${ }^{16}$. Además, debe tenerse en cuenta también la muy diferente distribución de los asentamientos dentro de cada municipio: si en la mitad sur de la península la concentración es prácticamente absoluta hasta el punto de coincidir un municipio con un único núcleo de poblamiento, en Galicia y Asturias la distribución es tan dispersa que cada municipio habitualmente incluye decenas de pueblos y localidades organizados administrativamente en "parroquias" y "concejos".

Tabla 5. Número total de municipios según su población (2018)

\begin{tabular}{|c|c|c|c|c|c|c|c|c|c|c|}
\hline $\begin{array}{l}\text { Comunidades } \\
\text { autónomas }\end{array}$ & (A) & (B) & (C) & (D) & (E) & $(F)$ & (G) & (H) & (I) & (J) \\
\hline Andalucía & 778 & 2 & 107 & 104 & 308 & 175 & 70 & 10 & 2 & 10.801 \\
\hline Aragón & 731 & 199 & 344 & 83 & 81 & 20 & 3 & 0 & 1 & 1.800 \\
\hline Asturias & 78 & 0 & 9 & 9 & 29 & 24 & 5 & 2 & 0 & 13.206 \\
\hline Canarias & 88 & 0 & 0 & 1 & 28 & 34 & 21 & 4 & 0 & 24.595 \\
\hline Cantabria & 102 & 2 & 16 & 17 & 46 & 16 & 4 & 1 & 0 & 5.697 \\
\hline Castilla y León & 2.248 & 679 & 1.103 & 214 & 193 & 44 & 11 & 4 & 0 & 1.078 \\
\hline Castilla-La Mancha & 919 & 258 & 261 & 121 & 204 & 59 & 15 & 1 & 0 & 2.214 \\
\hline Cataluña & 947 & 34 & 304 & 150 & 249 & 146 & 54 & 9 & 1 & 7.871 \\
\hline Com. Valenciana & 542 & 24 & 124 & 76 & 163 & 91 & 60 & 3 & 1 & 9.100 \\
\hline Extremadura & 388 & 9 & 111 & 95 & 136 & 30 & 6 & 1 & 0 & 2.765 \\
\hline Galicia & 313 & 0 & 5 & 26 & 170 & 90 & 19 & 3 & 0 & 8.638 \\
\hline Islas Baleares & 67 & 0 & 3 & 3 & 23 & 26 & 11 & 1 & 0 & 17.322 \\
\hline La Rioja & 174 & 60 & 74 & 12 & 19 & 7 & 1 & 1 & 0 & 1.796 \\
\hline Madrid & 179 & 10 & 18 & 19 & 52 & 45 & 25 & 9 & 1 & 36.349 \\
\hline Murcia & 45 & 0 & 1 & 2 & 5 & 20 & 15 & 2 & 0 & 32.757 \\
\hline Navarra & 272 & 42 & 111 & 36 & 61 & 18 & 3 & 1 & 0 & 2.358 \\
\hline País Vasco & 251 & 0 & 62 & 39 & 79 & 52 & 15 & 4 & 0 & 8.638 \\
\hline Ceuta y Melilla & 2 & 0 & 0 & 0 & 0 & 0 & 2 & 0 & 0 & 84.937 \\
\hline España & 8.124 & 1.319 & 2.653 & 1.007 & 1.846 & 897 & 340 & 56 & 6 & 5.730 \\
\hline $\begin{array}{l}\text { (A) Municipios } \\
\text { (B) Municipios de ho } \\
\text { (C) Municipios entre } \\
\text { (D) Municipios entr } \\
\text { (E) Municipios entre } \\
\text { (F) Municipios entre } \\
\text { (G) Municipios entr } \\
\text { (H) Municipios entr } \\
\text { (I) Municipios con } \\
\text { (J) Promedio de pob }\end{array}$ & $\begin{array}{l}\text { sta } 100 \\
101 \text { y } 5 \\
501 \text { y } 1 \\
1.001 \text { y } \\
5.001 \text { y } \\
20.001 \\
100.00 \\
\text { ás de } 50 \\
\text { ación pe }\end{array}$ & $\begin{array}{l}\text { habitar } \\
00 \text { habi } \\
000 \text { ha } \\
5.000 \\
20.000 \\
\text { y } 100.0 \\
\text { y } 500 \text {. } \\
0.000 \text { l } \\
\text { o munt }\end{array}$ & $\begin{array}{l}\text { antes } \\
\text { bitantes } \\
\text { abitante } \\
\text { habitan } \\
00 \text { habit } \\
000 \text { hab } \\
\text { abitante } \\
\text { cipio }\end{array}$ & $\begin{array}{l}\text { s } \\
\text { tes } \\
\text { antes } \\
\text { itantes } \\
\text { s }\end{array}$ & & & & & & \\
\hline
\end{tabular}

Fuente: Registro de entidades locales del Ministerio de Hacienda y Administraciones Públicas

Con todo, la mayor problemática resulta ser el imparable declive demográfico que, desde hace décadas, afecta a la mayor parte de las provincias españolas, castigadas por el éxodo rural y por la falta de renovación generacional (Fariña, 1977;

16 En Burgueño \& Guerrero (2014: 17-25) se presenta una detallada caracterización de las problemáticas actuales en las dimensiones (en superficie y en población) de los municipios españoles. 
García \& Sánchez, 1997). La pérdida continua de habitantes y el envejecimiento de los censos, combinado con un mapa municipal intocado (e intocable) genera un panorama desolador que eleva el tema de la administración de un territorio cada vez más despoblado a ser "cuestión de Estado". Así, en 2018, 4979 municipios (un $61,3 \%$ del total) no superaban los 1000 habitantes (concentrando el 3,15\% del total de la población de España), siendo la situación especialmente preocupante en seis provincias (Ávila, Burgos, Salamanca, Soria, Teruel, Zamora) en las que dicho porcentaje supera el $90 \%$. Esta situación no es un problema del conjunto de España, sino que se concentra principalmente en Castilla y León donde el 79,3\% del total de municipios cuenta con menos de 500 habitantes, y en Aragón, Castilla-La Mancha y Cataluña que tienen, cada una, más de 300 municipios de escasa población. En apenas menos de 20 años (entre 2000 y 2018) el número de municipios que no superan los 100 habitantes ha pasado de 928 a 1319. Según un informe de la Federación Española de Municipios y Provincias, más de 4000 municipios se encuentran en riesgo (moderado, alto o muy alto) de extinción (todos los de menos de 500 habitantes más una buena parte de los que tienen entre 500 y 1000) (FEMP, 2017). Nueve municipios cuentan con menos de 10 habitantes: se da el caso extremo de Illán de Vacas (provincia de Toledo) en el que, en 2014, constaba empadronada una sola persona (el alcalde), si bien en la actualidad son tres vecinos: después de que en los años 1990 rechazara un proyecto de fusión con un municipio vecino, hoy resulta aún más sorprendente la resistencia de este municipio (como tantos otros) a desaparecer, y más teniendo en cuenta que ni la LRSAL de 2013 (que, recordémoslo, busca "racionalizar" la administración local) amenaza la existencia de este "pueblo-fantasma"... si el Ayuntamiento de Illán de Vacas no solicita iniciar un procedimiento de anexión (Juez, 2014).

Tal y como afirma Mayte Salvador (2012: 62), desde la óptica de la prestación de servicios públicos, es obvio que el mapa municipal muestra grandes deficiencias y debido a su elevado número y heterogeneidad, conviven ejemplos de prestación eficiente de servicios públicos, con otros claramente ineficientes en la utilización de los recursos públicos. Pero parece simplista pensar que la reducción de municipios pueda llevar aparejada automáticamente una reducción de los costes en la prestación de los servicios. Parecería óptimo poder estudiar cada servicio para determinar cuáles se prestarían de manera más eficiente utilizando economías de escala y cuáles tendrían que seguir prestándose con independencia de que el núcleo urbano se constituya, o no, como entidad municipal. Los déficits en la prestación de los servicios básicos no obedecen tanto a la fragmentación del mapa municipal, como a la dispersión de la población en diferentes núcleos (Bel, 2012; Monasterio, 2000).

\subsection{Los enclaves y los límites municipales con formas caprichosas}

Los enclaves suponen una singularidad territorial cuyos orígenes se remontan a los de la misma formación de los municipios, ya sea en el siglo XIX o durante la Edad Media. Las razones de su existencia se atribuyen tanto a cuestiones históricas y geográficas como económicas (derechos de paso a caminos, ríos o pastizales, antiguas propiedades, jurisdicciones señoriales, etc.) si bien no se descarta, en ocasiones, el simple equívoco cartográfico (Ballester, 1968). 
En España existen más de 700 enclaves muchos de los cuales no presentan problemáticas especiales (Carnicer, 1995; Burgueño \& Guerrero, 2014: 27-31). De todos ellos quizá es adecuado destacar tres, por sus dimensiones territoriales, por tratarse ellos mismos de municipios, y por situarse fuera de los confines compactos de la provincia y de la comunidad autónoma a la que pertenecen ${ }^{17}$. De la especial situación de Villaverde de Trucios (perteneciente a la comunidad autónoma de Cantabria) y del Condado de Treviño (de Castilla-León) hay referencias documentadas desde el siglo XVI, pero su problemática es hoy especialmente trascendente cuando su posible integración en el País Vasco, donde están enclavados, tiene notables implicaciones políticas, culturales — enseñanza del euskera - y sobre todo económicas —ante las especiales condiciones financieras que disfruta el País Vasco-. Ambos han reivindicado en varias ocasiones la terminación de su condición de enclaves y desde la década de 1980 mantienen abiertos sendos contenciosos políticos-jurídicos.

El origen de la singular posición de Llívia (enclave español de $12,84 \mathrm{~km}^{2}$ en territorio francés) está en el mismo Tratado de los Pirineos de 1659 que partió Cataluña por su parte norte: en el Tratado se mencionaba que se cedían al reino de Francia los "pueblos" de la vertiente septentrional de los Pirineos, de manera que Llívia, por su rango de "villa", escapó a aquella cesión. Si bien durante muchos años esta anomalía creó graves problemas a sus habitantes, en la actualidad el Tratado de Schengen y la desaparición de las barreras internas de la Unión Europea ha supuesto el fin del aislamiento, a pesar de que formalmente el enclave sigue existiendo (Ruiz del Castillo, 1976).

Una problemática similar presentan los términos municipales con formas caprichosas: igual como los enclaves, cuando estas formas extrañas no afectan áreas pobladas o zonas que contienen infraestructuras y servicios, resultan simples anécdotas y singularidades del proceso histórico de formación de los límites y fronteras y que incluso puede ser significativo conservar. En caso contrario, los canales previstos (agregación-segregación, parcial o total) pueden resolver situaciones comprometidas, ya que la misma legislación reconoce estas situaciones como disfuncionalidades (FMC, 1995).

\subsection{Problemáticas en la transgresión de límites municipales}

El mapa municipal heredado mantiene numerosos y a veces seculares litigios de límites entre municipios vecinos, ya sea por unos pocos metros de terreno, la vertiente de una montaña, una playa, etc. Estos contenciosos acostumbran a originarse en deslindes poco claros y/o en zonas con fuertes intereses especulativos.

Si bien el crecimiento de las ciudades no es un fenómeno nuevo, desde los años 1950 en España la expansión urbana se manifiesta como tendencia imparable. En ocasiones el crecimiento llega hasta los límites de los respectivos términos municipales y los trasciende: si Madrid solucionó esta problemática anexionándose los municipios colindantes, en otras ciudades como Barcelona hoy su casco urbano se confunde con los de casi todos sus vecinos, hasta el extremo de que las aceras de una misma calle pertenecen a diferentes municipios.

17 Según el Registro de Entidades Locales de España, editado por el Ministerio de Administraciones Públicas en 2000, existen todavía 24 enclaves de unas provincias en otras, de ellos, 10 de unas Comunidades Autónomas en otras (MAP, 2000). 
Un caso similar pero que alcanza dimensión internacional es el del paso fronterizo de El Portús donde se desarrolló un núcleo de población sobre la misma línea de frontera internacional por la que, por casi 500 metros, discurre coincidiendo con el tramo de la carretera N-II: el lado este de la carretera queda en la vertiente española, adoptando el nombre de Els Límits, y el lado oeste es oficialmente francés y conocido como El Portús.

Un fenómeno con problemáticas similares es el de las urbanizaciones de segunda residencia o en zonas turísticas: casi siempre situadas en áreas rurales, crean una estructura y acondicionamientos prácticamente urbanos con la consiguiente demanda de servicios públicos y personales que pueden alterar la economía y la idiosincrasia propias del municipio afectado. En muchas ocasiones estas urbanizaciones transgreden los límites estrictos de un municipio, dificultando actuaciones urbanísticas conjuntas.

A menudo sucede también que, por proximidad, tradición, mayor oferta o mejores comunicaciones, la provisión de ciertos servicios, equipamientos e infraestructuras de un núcleo de poblamiento se realiza en un municipio distinto al cual pertenece. En otras ocasiones son las mismas grandes infraestructuras (sobre todo las autopistas, pero también los ferrocarriles, embalses, aeropuertos, etc.) las que aíslan partes de un municipio, propiciando que tengan una relación más intensa con municipios vecinos.

La legislación reconoce todos estos hechos como disfuncionalidades y, pues, como motivo de alteración de términos municipales pero la solución también puede llegar por la creación de mancomunidades de servicios o de áreas metropolitanas en el caso de las conurbaciones.

\subsection{Cuestiones de toponimia}

La práctica totalidad de municipios de Cataluña recuperaron la grafía catalana de su toponimia inmediatamente después de las primeras elecciones locales democráticas (1979), siendo desde entonces su denominación oficial exclusivamente en catalán. En el caso de otras comunidades autónomas como el País Vasco, la Comunidad Valenciana, las Islas Baleares y Galicia el proceso fue mucho más lento y, a menudo, se optó por una denominación doble conjunta en castellano y en catalán/vasco/gallego como topónimo oficial de muchos de sus municipios.

Como una más de las múltiples herencias del franquismo, cabe destacar la pervivencia de toponimia impuesta durante dicho periodo y que rememora al dictador o a personajes del régimen. Es significativo remarcar que, a pesar que el dictador falleció en 1975, que España se dotó de una nueva Constitución en 1978, que los ayuntamientos son elegidos democráticamente desde 1979 y, sobre todo, que desde 2007 existe una "Ley de memoria histórica" (suspendida de facto desde 2013 al no dotarla de presupuesto) que insta a "establecer medidas en favor de quienes padecieron persecución o violencia durante la guerra civil y la dictadura", la eliminación de la toponimia franquista ha sido un proceso muy lento, del que todavía quedan numerosos ejemplos ${ }^{18}$.

18 En 2018 todavía quedaban miles de calles con denominaciones propias de la dictadura, observándose por parte de numerosos ayuntamientos, en muchas ocasiones, una férrea resistencia a cambiarlos o recuperar los nombres anteriores, a pesar de que la legislación así lo obliga. 
Así, si el Ferrol (provincia de La Coruña) siguió siendo "del Caudillo" hasta 1982, Barbate de Franco (Cádiz) se mantuvo hasta 1998, Villafranco del Delta (Tarragona) hasta 2003, y Bardena del Caudillo (Zaragoza) hasta 2008, entre muchos otros casos. En la actualidad diversos municipios y entidades locales menores todavía conservan el recuerdo del dictador o de sus generales en sus denominaciones oficiales ${ }^{19}$. El caso de Guadiana del Caudillo (Badajoz), cuyos orígenes se remontan a 1950 fundado como poblado de colonización, es remarcable por ser uno de los municipios de reciente independencia (2012) y por haber celebrado, ese mismo año, una consulta popular que decidió mantener la mención al Caudillo, a pesar de contradecir la Ley de memoria Histórica.

\section{Algunas reflexiones finales}

El repaso sistemático a la normativa sobre las alteraciones del tramado municipal a lo largo de casi 200 años hace patente una doble realidad: por un lado, se constata la excesiva fragmentación y la estructura problemática del mapa municipal español, y por el otro se evidencia que no ha habido en ningún momento una política firme o una legislación específica para solventarlo, aunque siempre ha existido una normativa que podía ser utilizada para ello (Font, 2013; Font \& Galán, 2014; García Álvarez, 2004, 2008). De hecho, la tendencia ha ido en dirección contraria: en 2017 existen 95 municipios más que en 1979, cuando tuvieron lugar las primeras elecciones locales tras la dictadura de Franco.

A pesar de que, como se indicaba, la LRSAL de 2013 incentiva las fusiones y prohíbe las segregaciones de pueblos de menos de 5000 habitantes, desde entonces han aparecido una decena de nuevos municipios, todos ellos de entre 500 y 2500 habitantes ${ }^{20}$.

A falta, pues, de una política global y sistemática al respecto (que ni tan solo las pretensiones de "racionalización y sostenibilidad" de la LRSAL han conseguido implementar $^{21}$ ) (Font \& Galán, 2012b), las razones esgrimidas para crear nuevos municipios han sido, esencialmente, las reivindicaciones identitarias históricas y la posibilidad de manejar directamente impuestos y subvenciones. Por contra, la fusión o agregación de municipios, en las pocas y aisladas veces que se ha dado, ha sido para mejorar la provisión de servicios y equipamientos (en economías de escala) y por

19 Aunque la situación va revertiéndose, a mediados de 2018 seguían siendo oficiales los topónimos de Llanos del Caudillo (Ciudad Real), Alberche del Caudillo (Toledo), Villafranco del Guadalhorce (Málaga), Guadiana del Caudillo y Villafranco del Guadiana (Badajoz), Alcocero de Mola (Burgos), Quintanilla de Onésimo (Valladolid), San Leonardo de Yagüe (Soria), Queipo de Llano (Sevilla). La localidad de Azaña (Toledo) había sido denominada así desde la Edad Media, pero en 1936, al coincidir este topónimo con el apellido del presidente de la II República, la dictadura lo cambió por Numancia de la Sagra. Y todavía sigue así.

20 La falta de voluntad política es más que evidente en los argumentos expresados por el Ministerio de Hacienda y Administraciones Públicas, cuando afirma que si el expediente de segregación ya estaba iniciado, el límite de los 5000 habitantes no se aplica, de manera que otra decena de municipios tienen ya su independencia en marcha. La "racionalidad" de la LRSAL tampoco se aplicó en la única fusión observada ya que el nuevo alcalde se triplicó el sueldo de manera que el ahorro previsto de $60.000 €$ se quedó en apenas 6.000 .

21 Ante las dimensiones de la problemática, diversas han sido las propuestas y sugerencias sobre la reforma del mapa municipal lanzadas por diversos estamentos y organismos: Salvador (2012: 58-60) sintetiza buena parte de ellas, entre las que destacan FDGL (2011, 2012), FEMP/MAP (1999), MAP (2005), Velasco (2011), Círculo de Empresarios (2011), así como Rodríguez (2005, 2009) y López Ramón (2010). 
abaratar costes de gobierno ya que, si bien los cargos municipales de pueblos pequeños no cobran o cobran poco, un ayuntamiento y la estructura municipal a su entorno siempre generan una cantidad mínima de gastos. Si, pues, las razones de fusión o de segregación son habitualmente de tipo económico, el proceso de implementación (o de freno a dicha implementación) es puro juego político, tanto al nivel local propiamente dicho (dado que la iniciativa y la autorización surge siempre de los ayuntamientos implicados, estos pueden facilitar -o no- las cosas como parte de pactos, favores debidos o promesas electorales) como a partir de las estrategias generales de los partidos políticos: de hecho, fusionar municipios comporta eliminar cargos (y, pues, presencia pública) para los militantes de los partidos (aunque su peso sea mínimo). Además, dado que las poderosas, influyentes y boyantes diputaciones provinciales se constituyen a partir de los resultados electorales municipales, para los partidos políticos, obtener cuotas de poder a escala municipal (alcaldes y concejales) significa poder nutrir y controlar las funciones y actividades de dichas diputaciones.

Como consecuencia de todo ello, $\mathrm{y}$ ante las grandes dificultades para llevar a cabo una sistemática revisión del mapa municipal, a la administración local española se le impone el reto de diferenciar el territorio propiamente "político" (o ámbito de identidad ciudadana que permite desarrollar la democracia a través de la participación directa y como exponente de la representatividad más genuina ${ }^{22}$ ) del territorio de "gestión" más idóneo para hacer operativa la administración pública a nivel local, asegurando el bienestar y unas mismas condiciones y calidad de vida para toda la población. Ambos espacios no necesariamente han de enmarcar territorios diferentes, pero está claro que no obligatoriamente han de coincidir en el municipio, tal como ha sido entendido mayoritariamente hasta hoy.

El primer paso de toda reforma sigue siendo, pues, una revisión de los contenidos (atribuciones, competencias, poder, financiación) que han de caracterizar un municipio, delimitando cuales de estos contenidos pueden ser atribuidos a mancomunidades, comarcas, diputaciones, gobierno autónomo o gobierno central: una vez revestido nuevamente de plenos poderes y plena autonomía (jurídica, legislativa, de recursos, etc.), reconocido su papel de representante popular y liberado de las responsabilidades superfluas de prestación de servicios, el municipio podrá abandonar su tradicional posición de debilidad.

\section{Bibliografía}

Acadèmia de Jurisprudència i Legislació de Catalunya (1984) "La reforma de l'administració local de Catalunya", en Enric Lluch \& Oriol Nel·lo, El debat de la divisió territorial de Catalunya. Barcelona: Diputació de Barcelona, 345-376 (original de 1978).

ACM [1986] Congrés per la defensa del petit municipi. Ponències, conferències, comunicacions $i$ conclusions. No fem de Catalunya un desert. [Barcelona]: Associació Catalana de Municipis.

22 "La fusión de municipios reduce la posibilidad real de incidencia de los ciudadanos sobre las políticas municipales. Los municipios son instituciones políticas, representativas y de participación para los ciudadanos que en ellos habitan. El sentimiento de arraigo y de pertenencia al territorio favorece la participación ciudadana y la calidad de la democracia, tal y como demuestra el dato empírico de que la participación en las elecciones municipales es mayor cuanto menor es la población municipal" (Salvador, 2012: 62). 
Albrich, Sergi (2014) La línia de terme, una eina bàsica per la gestió municipal. Barcelona: Associació Catalana de Municipis i Comarques \& Càtedra Enric Prat de la Riba d'Estudis Jurídics Locals.

Arias, F. (1980) “Los pequeños municipios en las áreas metropolitanas”. CEUMT, núm. 23, 44-47.

Arqué, Maite; García, Àngela \& Mateu, Xavier (1979) "Las agregaciones de municipios en las áreas de montaña. El caso del Alto Pirineo Catalán”. Ciudad y Territorio, núm. 4, 6574.

Ballester, Ignacio (1968) "Los enclaves municipales en España". Revista de Estudios de la Vida Local, núm. 111, 405-413.

Barranco, Rafael (1993) Creación y segregación de municipios. Madrid: Marcial Pons.

Bel, Germà (2012) "Servicios locales: tamaño, escala y gobernanza", en Informe IEB sobre Federalismo Fiscal'11. Barcelona: Institut d'Economia de Barcelona-Fundación ICOInstituto de Estudios Fiscales-Institut d'Estudis Autonòmics.

Benito, Juan \& de la Vega, Sofía (2003) “Consideraciones geográficas sobre la superficie de los municipios de Andalucía”. Espacio y Tiempo: Revista de Ciencias Humanas, núm. 17, 9-28.

Burgueño, Jesús (2001) “Geografía y administración. Proyectar territorios en el siglo XXI”. Boletín de la $A G E$, núm, 32, 191-207.

Burgueño, Jesús (2004) "El eterno debate sobre la reforma del mapa municipal. El caso de Cataluña". Revista de Geografía, núm. 3, 7-33.

Burgueño, Jesús \& Gras, M. Mercè (2014) Atles de la Catalunya senyorial. Els ens locals en el canvi de règim (1800-1860). Barcelona: Institut Cartogràfic i Geològic de Catalunya / Rafael Dalmau Editor.

Burgueño, Jesús \& Guerrero, Montse (2014) "El mapa municipal de España. Una caracterización geográfica”. Boletín de la $A G E$, núm. 64, 11-36.

Burgueño, Jesús \& Lasso de la Vega, Ferran (2002) Història del mapa municipal de Catalunya. Barcelona: Direcció General d'Administració Local.

Burgueño, Jesús \& Mòdol, Josep Ramon (2016) “Termes tradicionals dels pobles del Pallars Sobirà", en Béns comunals. Un sistema d'organització del passat per gestionar el present. [s.l.]: Fundació del Món Rural y Institut per al Desenvolupament i la Promoció de l'Alt Pirineu i Aran, 61-105.

Capdevila, Joan (2005) "Els treballs de delimitació municipal del Instituto Geográfico Nacional a Catalunya, 1909-1930”. Treballs de la Societat Catalana de Geografia, núm. 60, 45-69.

Carnicer, Ramon (1995) Viaje a los enclaves españoles. Sabadell: Ausa.

Casassas, Lluís (1982-83) "Hacia unos nuevos principios de ordenación territorial de base municipal en Cataluña". Revista de Geografia, núm. XVI-XVII, 73-86.

Casassas, Lluís (1986) "Un debat nou sobre la divisió territorial de Catalunya: els municipis, les comarques i el poder”. Quaderns d'alliberament, núm. 12, 39-50.

Casassas, Lluís \& Clusa, Joaquim (1981) L'organització territorial de Catalunya. Barcelona: Fundació Jaume Bofill.

Castelao, Julio (1994) El término municipal. Extensión y alteraciones. Madrid: El Consultor de los Ayuntamientos y de los Juzgados.

Castells, José Manuel (1983) "Nueva problemática de las alteraciones territoriales municipales". RAP, núm. 100-102, vol. 3, 2159-2186.

Círculo de Empresarios (2011) Cómo reformar las Administraciones territoriales. Libro Marrón. Madrid: Círculo de Empresarios. 
Comissió d'Experts creada per acord del Govern de 3 d'abril de 2000, a instàncies dels diferents grups del Parlament de Catalunya (2000) Informe sobre la revisió del model d'organització territorial de Catalunya. [Barcelona]: Generalitat de Catalunya, Departament de Governació i Relacions Institucionals.

Datzira, Sebastià (2012) “La delimitació municipal i l'elaboració del mapa municipal de Catalunya”. Revista catalana de Geografia, vol. XVII, núm. 45 [En línea. URL: $<$ http://www.rcg.cat/articles.php?id=235>. Consultado el 23 de junio de 2018].

DGCL (2008) Variaciones de los municipios de España desde 1842. Madrid: Ministerio de Administraciones Públicas, Secretaría General Técnica, Dirección General de Cooperación Local.

Díez, Florentino-Agustín (1966) "El desarrollo económico-social y el municipio-comarca". Revista de Estudios de la Vida Local, núm. 145, 22-30.

Díez, Juan José (coord.) (2006) La planta del gobierno local. Madrid: Fundación Democracia y Gobierno Local.

Durán, Francisco Javier (2016) La fusión de municipios como estrategia. Madrid: Dykinson.

Durán, Francisco Javier (2017) "Una cuestión histórica de actualidad: la reforma de planta local en España”. Consultor de los ayuntamientos y de los juzgados, núm. 2, 174-188.

Fariña, José (1977) Agonía y muerte del municipio rural. Madrid: Imp. Sáez.

FDGL (2011) Libro Verde. Los Gobiernos Locales intermedios en España. Diagnóstico y Propuestas para reforzar el valor institucional de las diputaciones provinciales y demás Gobiernos locales intermedios en el Estado Autonómico. Madrid: Fundación Democracia y Gobierno Local.

FDGL (2012) Elementos para un debate sobre la Reforma Institucional de la Planta Local en el Estado Autonómico. [Madrid]: Fundación Democracia y Gobierno Local.

FEMP (2017) Población y despoblación en España 2016. El 50\% de los municipios españoles en riesgo de extinción. [s.l.]: Comisión de Despoblación, Federación Española de Municipios y Provincias.

FEMP/MAP (1999) El Pacto Local. Medidas para el desarrollo del Gobierno Local. Madrid: Federación Española de Municipios y Provincias y Ministerio de Administraciones Públicas.

Ferret, Joaquim (1986) “Uniformitat i varietat en la regulació del municipi”. Autonomies, núm. 4, 61-79.

FMC (1995) Municipis amb nuclis agregats. Barcelona: Federació de Municipis de Catalunya.

Font, Tomàs (2013) “La reforma de la planta local”. Revista Española de Derecho Administrativo, núm. 158, 11-16.

Font, Tomàs \& Galán, Alfredo (2012a) "Gobierno local y reorganización territorial: ¿la reforma vendrá de Europa?”. Anuario del Gobierno Local 2011. Madrid: Fundación Democracia y Gobierno Local/Instituto de Derecho Público, 11-39.

Font, Tomàs \& Galán, Alfredo (2012b) "Racionalización y sostenibilidad de la Administración Local: ¿es esta la reforma?”. Anuario del Gobierno Local, núm. 1, 11-43.

Font, Tomàs \& Galán, Alfredo (2014) "Los retos actuales del gobierno local: repolitización, diversificación e interiorización”. Anuario del Gobierno Local, núm. 1, 11-45.

Gallego, Alberto (1955) Municipios grandes, medianos y pequeños. Madrid: Instituto de Estudios de la Administración Local.

García, Javier (1983) El origen del municipio constitucional. Madrid: Instituto de Estudios de la Administración Local.

García, Arlinda \& Sánchez, Dolores (1997) "Población y tamaño municipal: reflexiones a partir del censo de 1991”. Estudios Geográficos, núm. 229, 593-623. 
García Álvarez, Jacobo (2004) "Mapa municipal y políticas territoriales en España. Elementos para un debate". Xeográfica. Revista de Geografía, Territorio y Medio Ambiente, núm. 4, 7-23.

García Álvarez, Jacobo (2008) “L’evolució dels territoris locals a Espanya (1985-2005). De les inèrcies del mapa municipal a la construcció d'una nova geometria supramunicipal”, en J. Tort, V. Paül \& J. Maluquer (eds.) L'organització del territori, un repte per al segle XXI? Cabrera de Mar: Galerada / Barcelona: Universitat Catalana d'Estiu, 151-187.

García Pascual, Pedro (1960) "El problema de los pequeños municipios en España". Revista de Documentación Administrativa, núm. 27, 39-44.

Garrido-Villén, Natalia; Berné Valero, José Luis; Antón Merino, Alberto \& Anquela Julián, Ana Belén (2014) "Jurisdictional boundaries in Spain, survey and marking of boundaries in Teruel (Spain)”. Survey Review, núm. 46, vol. 336, 205-212.

Gavira, Carmen (1980) "Municipios pequeños y pequeños municipios. Las bases geográficas y demográficas del poder local en España". CEUMT, núm. 23, 34-44.

Gómez Mendoza, Josefina \& García Álvarez, Jacobo (2001) "La pervivencia y la resistencia al cambio de la organización municipal”, en A. Gil \& J. Gómez Mendoza (dirs.) Geografía de España. Barcelona: Ariel, 591-592.

Guerrero, Montse \& Burgueño, Jesús (2018) "Disfunciones territoriales municipales en Cataluña”. Boletín de la AGE, núm. 78, 302-328.

Hermosilla, Jorge \& Rodrigo, Carles (1997) “Cambios de límites de términos municipales en el territorio valenciano por actuaciones del INC-IRYDA”. Cuadernos de Geografía, núm. 61.

INE (1981) Relación de municipios desaparecidos desde principios de siglo. Madrid: Instituto Nacional de Estadística.

Izu, Miguel José (2011) La cuestión del mapa local desde una perspectiva europea. [En línea. URL: <http://webs.ono.com/mizubel/mapa2.pdf>. Consultado el 13 de noviembre de 2018].

Jordana de Pozas, Luis (1961) "Problemas de los pequeños municipios". Estudios de administración local y general, Madrid: Instituto de Estudios de la Administración Local, 603621.

Juez, J. A. (2014) “Un municipio hacia la extinción. El último vecino de Illán de Vacas”. La Tribuna de Toledo, 9 de enero [En línea. URL: <http://www.latribunadetoledo.es/noticia/Z7D658C85-BA79-055D8996F2FF6C5889F9/20140109/ultimo/vecino/illan/vacas>. Consultado el 12 de junio de 2018].

Lara, Juan Antonio (1966) “Administración local y reforma de la administración”. Revista de Documentación Administrativa, núm. 100, 415-421.

Liesa, Celso (1972) Reestructuración de términos municipales. Barcelona: Bayer.

López Vila, Carlos (1969) “La fusión e incorporación de municipios en España”. Revista de Estudios de la Vida Local, núm. 162, 266-267.

López Ramón, Fernando (2010) "Políticas ante la fragmentación del mapa municipal”. Revista de Estudios de la Administración Local y Autonómica, núm. 313-314, 67-104.

MAP (2000) Entidades locales en España (2000). Madrid: Ministerio de Administraciones Públicas.

MAP (2005) Libro Blanco para la reforma del Gobierno Local. Madrid: Ministerio de Administraciones Públicas.

Martín, Ramón (1964) La comarcalización de los pequeños municipios. Madrid: Secretaría General Técnica del Ministerio de la Gobernación.

Martín, Ramón (1987) Entes locales complejos. Madrid: Trivium. 
Martín-Retortillo, Sebastián (1961) "Problemas de los municipios rurales”. Problemas politicos de la vida local, Madrid: IEP, 273-308.

Masdeu, Francesc; Jiménez, Maria del Mar \& Ledo, Raül (2015) “La normalització de la delimitació municipal a Catalunya (2007-2015): una infraestructura bàsica per a la gestió territorial". Revista Catalana de Geografia, vol. XX, núm. 52 [En línea. URL: $<$ http://www.rcg.cat/articles.php?id=342>. Consultado el 10 de marzo de 2018].

Massó, Jaume \& Torres, Marc (2009) "La delimitació municipal a Catalunya". Revista Catalana de Geografia, vol. XIV, núm. 37 [En línea. URL: <http://www.rcg.cat/articles.php?id=161>. Consultado el 10 de junio de 2018].

Massó, Jaume; Torres, Marc \& Jiménez, M. Mar (2011) "La recuperació dels límits municipals històrics. Conveni DGAP-ICC (2005-2011)". Revista Catalana de Geografia, vol. XVI, núm. 43 [En línea. URL: <http://www.rcg.cat/articles.php?id=212>. Consultado el 12 de junio de 2018].

Mateu, Xavier (1988) La administración local y los servicios municipales, La Seu d'Urgell: MAB 6-Alt Pirineu.

Mateu, Xavier (1989) "El marc administratiu”, en 10 anys d'ajuntaments democràtics. Barcelona: Federació de Municipis de Catalunya, 71-102.

Meligrana, John (ed.) (2004) Redrawing Local Government Boundaries: An International Study of Politics, Procedures and Decisions. Vancouver: University of British Columbia Press.

Melón, Amando (1954) "Modificaciones del mapa municipal de España (1900-1950)". Estudios Geográficos, núm. 54, 137-147.

Melón, Amando (1974) "Modificaciones del mapa municipal de España en el intercensal 1961-1970”. Estudios Geográficos, núm. 134, 107-116.

Melón, Amando (1977) "Modificaciones del mapa municipal de España a través de un siglo (1857-60 a 1960)”. Estudios Geográficos, núm. 148-149, 829-850.

Mir, Josep (1991) La reforma del règim local a Catalunya. Barcelona: Escola d'Administració Pública de Catalunya.

Monasterio, Carlos (2000) "Política local, hacienda local y tamaño de los municipios". Revista del Instituto de Estudios Económicos, núm. 4, 99-110.

Morell, Luis (1972) Estructuras locales y ordenación del espacio. Madrid: Instituto de Estudios de la Administración Local.

Nadal, Francesc (1985) Política territorial y anexiones de municipios urbanos en España (siglos $X I X-X X)$. Barcelona: Pub. Universitat de Barcelona.

Nadal, Francesc \& Urteaga, Luis (2012) "La delimitació dels termes municipals", en Atles topogràfic-històric de Catalunya 1:50.000. Primeres edicions dels fulls de Catalunya del Mapa Topográfico de España. Barcelona: Institut Cartogràfic de Catalunya, 41-44.

Navarro, Javier (2001) "Las Mancomunidades de municipios en España. Una estrategia de desarrollo territorial de escala intermedia”, en Fernando Manero (coord.) Espacio natural y dinámicas territoriales. Homenaje al Dr. D. Jesús García Fernández. Valladolid: Universidad de Valladolid, 632-641.

Oliveras, Josep (1997) “Els límits municipals com a frontera”, en J. Domingo \& L. Mallart (coords.) A l'entorn de la frontera. Vilassar de Mar: Oikos-Tau, 53-70.

Orduña, Enrique (2003) "Nuevas aportaciones sobre el mapa municipal español”. Revista de Estudios de Administración Local, núm. 291, 779-826.

Perdigó, Joan (1987) El municipio y su territorio, alteración de términos municipales. Madrid: Banco de Crédito Local.

Rodríguez, Román (2005) Territorio y gobierno local en España. Un planteamiento de restructuración por fusión como realidad necesaria. Madrid: Thomson Civitas. 
Rodríguez, Román (dir.) (2009) Reformar la administración territorial. Municipios eficientes y viables. Oleiros: Netbiblo.

Rueda, Isabel; Camarasa, Josep Maria \& Mateu, Xavier (1987) "Diagnòstic del mapa municipal de Catalunya". Treballs de la Societat Catalana de Geografia, núm. 10-11, 129152.

Ruiz del Castillo, Ricardo (1976) Llivia (enclave español en Francia). Madrid: Servicio Geográfico del Ejército.

Salvador, Mayte (2012) "Retos y oportunidades para el gobierno local en tiempos de crisis". Cuadernos Manuel Giménez Abad, núm. 4, 55-64.

SCOT (1993) Informe sobre la segregació de municipis. Barcelona: Institut d'Estudis Catalans, Societat Catalana d'Ordenació del Territori.

Sosa, Francisco \& de Miguel, Pedro (1987) Creación, supresión y alteración de términos municipales. Madrid: Instituto de Estudios de la Administración Local.

Subdirección General de Estudios y Sistemas de Información Local (2009) Estudio sobre el Registro de Entidades Locales. Madrid: Ministerio de Política Territorial.

Ticó, Maria Isabel \& García, Maria Antònia (1994) "Recopilació de la documentació de delimitació municipal a Catalunya". Terra, núm. 22, 28-38.

Torres, Federico (1985) Las entidades locales menores en el derecho administrativo español. Madrid: Instituto de Estudios de la Administración Local.

Torres, Francesc (1999) Evolució del mapa municipal valencià. Simat de la Valldigna: La Xara.

Tort, Joan (1993) Les entitats municipals descentralitzades a Catalunya. Barcelona: Generalitat de Catalunya.

Tusell, Javier \& Chacón, Diego (1973) La reforma de la administración local en España (1900-1936). Madrid: Instituto de Estudios Administrativos.

Velasco, Francisco (2011) "La planta local en España: criterios para la toma de decisiones". Anuario de Derecho Municipal 2012. Madrid: Marcial Pons/UAM.

Villegas, Francisco (1973) "Concentración de municipios en la provincia de Granada". Estudios Geográficos, núm. 132-133, 701-719. 